\title{
REFUERZO DE VIGAS DE HORMIGÓN ARMADO CON LÁMINAS DE PRFV (PLÁSTICO REFORZADO CON FILTRO DE VIDRIO)
}

REINFORCEMENT OF REINFORCED CONCRETE BEAMS WITH PRFV SHEETS (REINFORCED PLASTIC WITH GLASS FILTER)

\author{
ALBERTO PEDRO BUSNELLI', RUBÉN EDGARDO LÓPEZ2², JORGE ADUE ${ }^{3}$ \\ 1 Universidad Nacional de Rosario. Argentina. busnelli@fceia.unr.edu.ar \\ 2 Universidad Nacional de Rosario. Argentina. relopez@fceia.unr.edu.ar \\ 3 Universidad Nacional de Rosario. Argentina. ccivil@fceia.unr.edu.ar
}

RESUMEN

El estudio de la utilización de láminas pultruídas de PRFV (Plástico reforzado con fibras de vidrio para incrementar la resistencia a flexión de vigas de hormigón armado. Se realizaron cuatro series de ensayos: En las dos primeras series se ensayaron vigas simplemente apoyadas para verificar la efectividad de distintos tipos de refuerzos. Se utilizaron telas de fibra de carbono, telas de fibras de vidrio y láminas pultruídas de fibras de vidrio. № se utilizaron láminas pultruídas de fibras de carbono porque su costo elevado desalienta la utilización en la reparación de estructuras en nuestro mercado y uno de los objetivos de este trabajo era justamente comprobar la posibilidad de sustitución de dichas láminas. Los resultados obtenidos demostraron la efectividad de las láminas de fibras de vidrio, significativamente más económicas que las de carbono, que constituyen por lo tanto una alternativa válida. Se pudo verificar que las láminas pultruídas quedaron prácticamente intactas fallando los sistemas de anclaje a las vigas. Se decidió entonces profundizar la investigación de los sistemas de anclaje de dichas láminas. En ese sentido se programó una tercera serie de ensayos dirigida a comparar la efectividad de los distintos sistemas. En ellos se utilizó una bisagra metálica auxiliar que permitió comparar las fuerzas de arranque de láminas encoladas, con diferentes anclajes extremos. Se ensayaron láminas solamente adheridas, láminas adheridas con el agregado de fajas de tela en los extremos y láminas adheridas con los extremos fijados con bulones de alta resistencia. Se pudo verificar la efectividad de las láminas adheridas y ancladas abulonadas. Los bulones le otorgan al sistema una resistencia poscrítica que le confiere una característica de ductilidad muy útil para las estructuras en zona sísmica. La cuarta serie se realizó para perfeccionar estos sistemas de anclaje abulonados.

PALABRAS CLAVE: Láminas pultruidas, PRFV, refuerzo de flexión, pultruded plates.
ABSTRACT

The study of the use of FRP pultruded sheets (Glass fiber reinforced plastic to increase the flexural strength of reinforced concrete beams.) Four series of tests were performed: in the first two series, beams were simply supported to verify the effectiveness of carbon fiber fabrics, glass fiber fabrics and pultruded sheets of glass fibers were used. Pultruded sheets of carbon fibers were not used because their high cost discourages the use in the repair of structures in our Market and one of the objectives of this work was precisely to verify the possibility of substitution of said sheets. The results obtained showed the effectiveness of the sheets of glass fibers, significantly cheaper than those of carbon, which are therefore a valid alternative It was verified that the pultruded sheets were practically Intact and the failure occurred in the anchors to the beams. It was then decided to deepen the investigation of the anchoring systems of said sheets. In that sense, a third series of tests was designed to compare the effectiveness of the different systems. Then an auxiliary metal hinge was used that allowed to compare the initial forces of glued sheets, with different extreme anchors. Only adhered sheets were tested, sheets adhered with the addition of fabric strips at the ends and sheets adhered with the ends fixed with bolts of high strength. The effectiveness of the bonded and anchored ablated sheets could be verified. The bolts give the system a postcritical resistance that gives it a very useful ductility characteristic for seismic zone structures. The fourth series was made to increase the performance of these bolted anchor systems.

KEYWORDS: pultruded plates, GFRP, flexural strengthening. 


\section{INTRODUCCIÓN}

La mayoría de los estudios realizados sobre el refuerzo de elementos en flexión mediante el empleo de materiales compuestos fibrorreforzados han apuntado a las fibras de carbono por ser éstas las de mejores propiedades mecánicas.

Los productos más comunes que se comercializan son las telas con espesores del orden de décima de $\mathrm{mm}$ y las láminas pultruídas cuyo espesor es de varios $\mathrm{mm}$. La capacidad mecánica que aportan las telas a las vigas de hormigón armado es relativa por la escasa sección agregada, no ocurre lo mismo con el refuerzo de losas en la que el aporte relativo de sección resistente es mayor.

Por el contrario, la utilización de láminas pultruídas ha demostrado ser una solución muy efectiva para el refuerzo de vigas. La mayor cantidad de fibras aportadas permite incrementar notablemente la capacidad flexional de los elementos intervenidos.

En Argentina, el alto costo de las fibras de carbono impidió una difusión masiva de su utilización en el mercado local. Además la mayoría de las intervenciones realizadas han sido con telas por volverse casi prohibitivo el uso de láminas.

Estas circunstancias lograron que se decidiera en la facultad profundizar el estudio de la aplicación de telas y perfiles pultruídos de fibras de vidrio. Estos productos son de fabricación nacional y tienen un costo muy inferior al de los elementos análogos realizados con fibras de carbono.

PRODUCTOS

TELAS UNIDIRECCIONALES

Se emplean como refuerzos de flexión y corte en elementos de hormigón armado y mampostería. $\mathrm{Su}$ contribución para el incremento de la resistencia flexional de vigas no es muy relevante pero en cambio pueden resultar adecuadas para el refuerzo de losas ya que al estar armadas con diámetros más pequeños, el aporte relativo de la sección de las telas es mucho más significativo.

En el caso de estructuras de mampostería, el uso de telas revolucionó el concepto de refuerzo porque no hay otro material de construcción de características comparables en lo que se refiere a propiedades mecánicas y a funcionalidad. El bajo módulo elástico de las fibras de vidrio, en este caso, constituye una ventaja frente a las fibras de carbono ya que éstas conforman refuerzos excesivamente rígidos para las mamposterías que al no acompañar las deformaciones se desprenden fácilmente.

\section{TELAS BIDIRECCIONALES}

Las telas bidireccionales tienen un campo de empleo más restringido. Su uso se limita al refuerzo de zonas con solicitaciones multidireccionales, aunque en estos casos muchas veces se prefiera el uso de varias capas de telas unidireccionales orientadas de manera diferente. También se usan como protecciones envolventes.

\section{MALLAS}

Las mallas son telas bidireccionales de trama abierta y son ideales para los refuerzos con matriz cementicia, ya que permiten el paso del mortero a través de su entramado. Para poder ser utilizadas en este tipo de solución, las mallas de fibra de vidrio tienen que tener un tratamiento protectivo que evite la reacción álcali agregado.

\section{BARRAS PULTRUÍDAS}

La utilización de barras pultruídas como refuerzo de elementos en flexión por el método NSM es una solución muy eficaz. Este método consiste en realizar una caladura en la zona a reforzar para introducir una barra o una lámina inmersa en una masa de resina epoxídica tixotrópica. Su uso es muy frecuente en aquellos países en los que los reglamentos de cálculo imponen recubrimientos elevados. En Argentina donde la mayor parte de las estructuras construidas ofrecen recubrimientos de 1 a $2 \mathrm{~cm}$, el diámetro de las barras de refuerzo a insertar se ve limitado y por lo tanto también se limita el aporte mecánico.

LÁMINAS PULTRUÍDAS

Las láminas pultruídas son los elementos más utilizados para el refuerzo a flexión de vigas de hormigón armado ya que ofrecen un importante aporte mecánico. sobre todo las láminas de fibras de carbono. Se utiliza láminas de fibra de vidrio. En comparación, presentan una resistencia inferior y una mayor deformación pero al ser mucho más económicas esa menor prestación se compensa con la aplicación de mayor cantidad de fibras.

Las láminas de fibra de vidrio son de mayor espesor ( 4 a 6 mm contra 1 a $2 \mathrm{~mm}$ de las láminas de carbono). Pueden ser adheridas con resinas epoxídicas pero además presentan la ventaja de poder ser ancladas mecánicamente mediante pernos minimizando el efecto de delaminación y permitiendo por lo tanto un mayor aprovechamiento del material. Este tipo de anclaje es posible por la menor fragilidad de la lámina. En los refuerzos con láminas pultruídas resulta imprescindible la colocación de anclajes para evitar 
la delaminación de extremos. En este tipo de elementos con gran rigidez transversal (a diferencia de las telas que acompañan las deformaciones) las tensiones de tracción por delaminación en extremos, conocidas como tensiones de peeling, son muy elevadas, por lo que se deben reforzar correctamente estas zonas con elementos que garanticen un anclaje adecuado.

ENSAYOS

Se realizaron cuatro series de ensayos. en el laboratorio de estructuras del IMAE (Instituto de Mecánica Aplicada y Estructuras (Facultad de Cs. Exactas, Ingeniería y Agrimensura de la Universidad Nacional de Rosario).

En la primera serie, se emplearon seis vigas de 19x45 cm de sección y $5 \mathrm{~m}$ de luz que fueron reforzadas con distintas capas de telas de fibras de carbono y láminas pultruídas de fibras de vidrio.

Para la segunda serie, se utulizaron ocho vigas de $14 \times 29 \mathrm{~cm}$ de sección y $3 \mathrm{~m}$ de luz reforzadas con telas de fibras de vidrio y láminas pultruídas de fibras de vidrio.

En la tercera serie, se fueron utilizados ocho pares de especímenes para ensayos de adherencia a través de fuerzas de tracción por flexión. Se elaboraron 16 probetas de 19x12 cm de sección y $75 \mathrm{~cm}$ de longitud que se vincularon con una lámina pultruída de fibra de vidrio de $150 \mathrm{~cm}$.

Para la cuarta serie se reutilizaron las probetas de la tercera serie para profundizar el estudio del sistema de anclajes abulonados.

PRIMERA SERIE

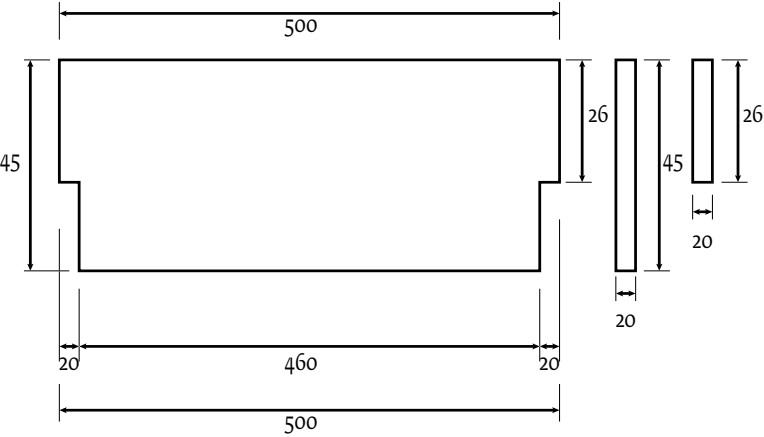

Figura 1. Geometría de las vigas.

Se ensayó una viga sin refuerzo como viga de referencia (V0). Cuatro vigas fueron reforzadas con capas de telas unidireccionales de fibra de carbono (V1, V2, V3 y V4) y una viga fue reforzada con láminas pultruídas de fibra de vidrio (V5).

Se buscó minimizar la delaminación del refuerzo colocando bandas de telas de fibra de carbono en los extremos en todas las vigas y en las últimas dos se agregaron fajas en la zona de aplicación de las cargas.

Los ensayos se realizaron en un pórtico reactivo vertical con dos gatos hidráulicos para la aplicación de las cargas. Las vigas se montaron sobre dos pilares de hormigón y el apoyo simple en ambos extremos se materializó mediante cilindros y placas metálicas interpuestas para permitir la libre deformación de las vigas.

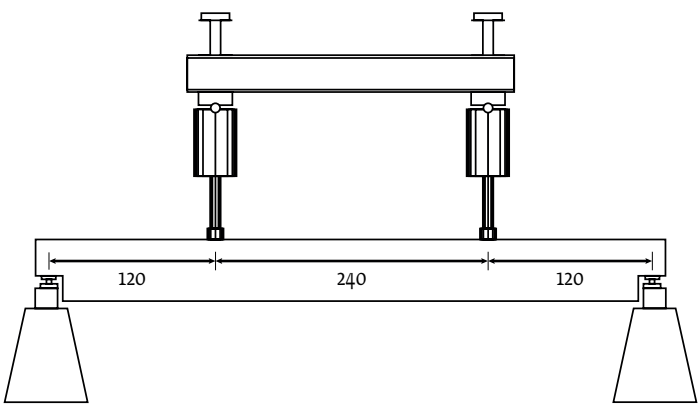

Figura 2. Esquema de los ensayos.
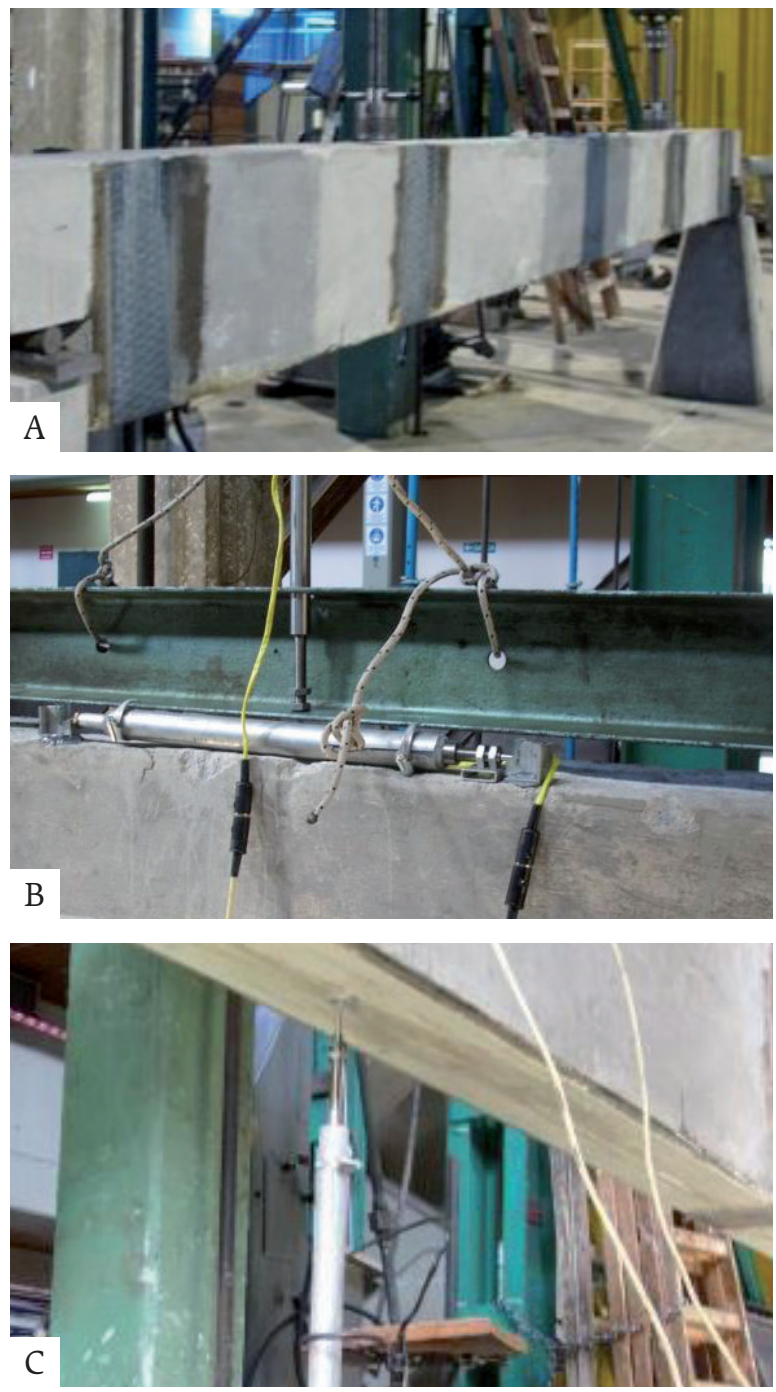


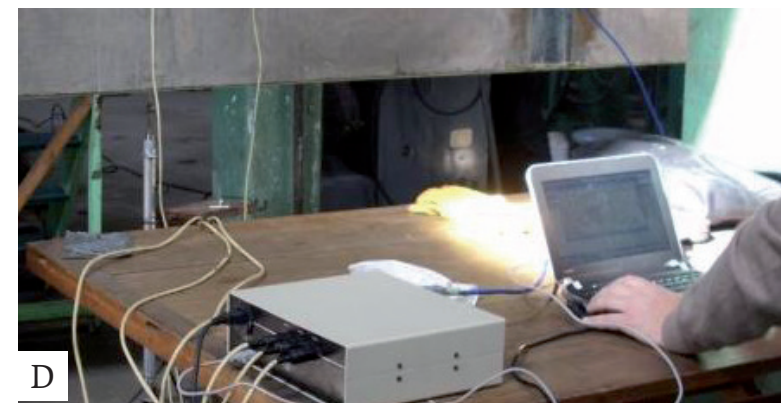

Figura 3. (a) Dispositivo de ensayo (b-c-d) Transductores de desplazamiento.

TIPOS DE FALLA

La viga de referencia V0 falló por compresión del hormigón en la zona central de la viga.

Las tres vigas reforzadas con telas de fibras de carbono V1, V2 y V3 fallaron por rotura del refuerzo en la zona de aplicación de la carga. En este punto es donde se produce la concomitancia del momento máximo con el corte máximo y se pudo observar la presencia de dislocamientos localizados. Esta forma de rotura se denomina CDC (Critical Diagonal Crack) debonding, o sea delaminación por fisuras diagonales críticas. Además de incrementar la carga de rotura, los refuerzos con telas disminuyeron la flecha.

Para controlar este fenómeno, en las vigas V4 y V5 se colocaron refuerzos transversales en las zonas de aplicación de las cargas, además de los refuerzos de extremos.

En la viga V4 la rotura del refuerzo se produjo en la zona central de la viga y la viga V5 falló por rotura de la cabeza comprimida manteniéndose intactas las láminas pultruídas de fibra de vidrio.
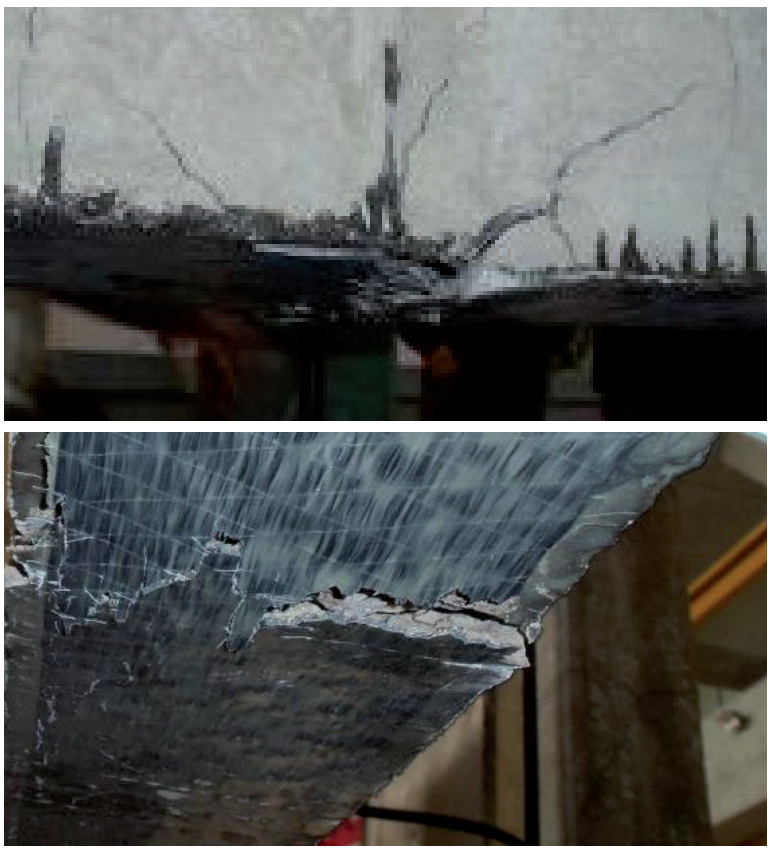

Figura 4. Rotura del refuerzo de fibras bajo carga puntual de viga V1.

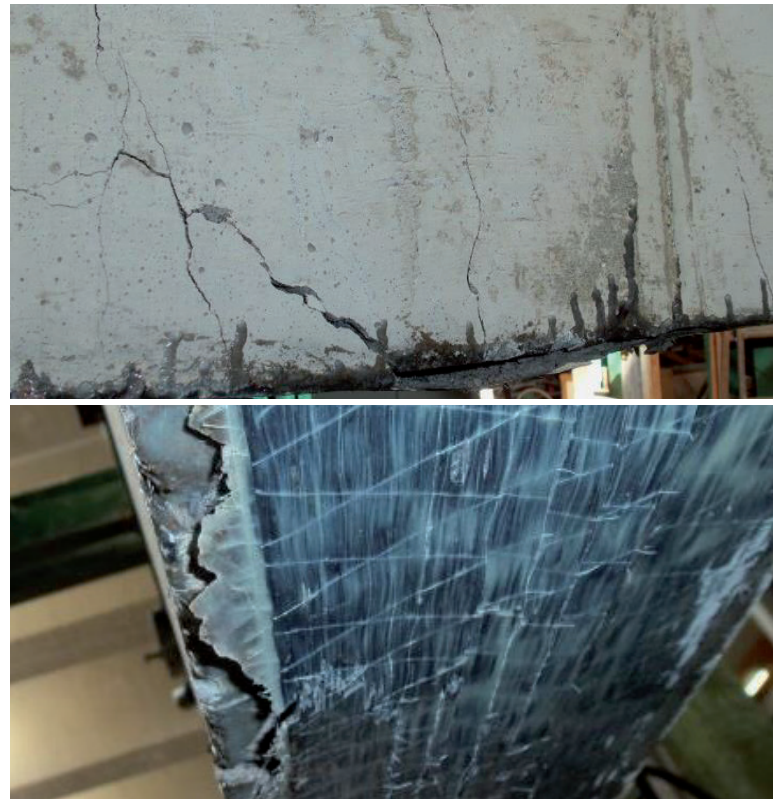

Figura 5. Rotura del refuerzo de fibras bajo carga puntual de viga V2.
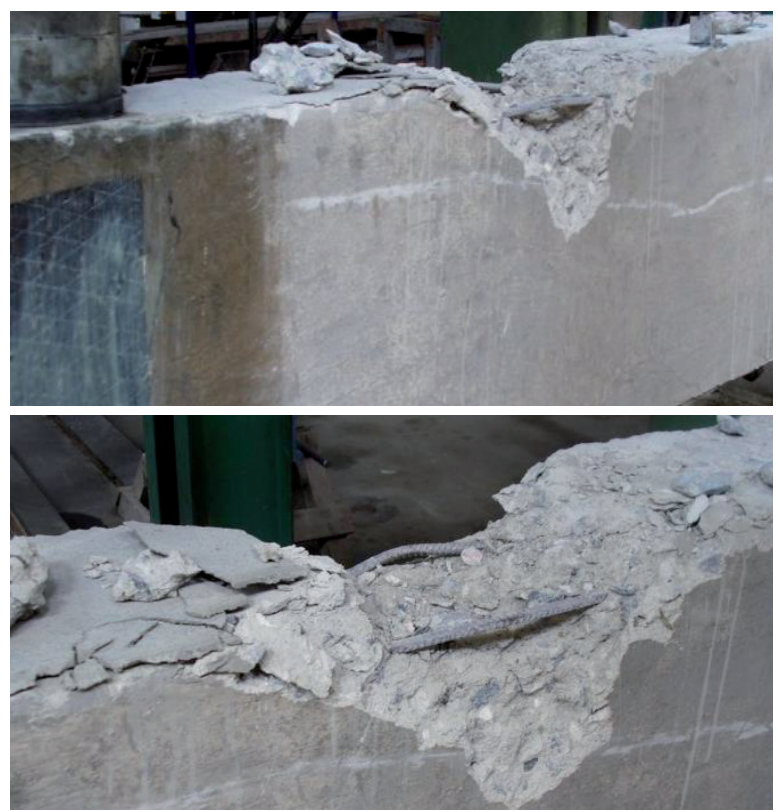

Figura 6. Falla por compresión del hormigón de viga V5 (refuerzo de fibras de vidrio intacto).

TABLA 1. RESUMEN DE RESULTADOS. CARGA DE ROTURA Y TIPO DE FALLA

\begin{tabular}{|c|c|c|c|c|c|}
\hline VIGA & $\begin{array}{r}\text { CANTIDAD } \\
\text { CAPAS }\end{array}$ & $\begin{array}{r}\text { CARGA } \\
\text { ROTURA POR } \\
\text { GATO [T] }\end{array}$ & $\begin{array}{r}\text { FLECA } \\
\text { MÁXIMA } \\
\text { [CM] }\end{array}$ & $\begin{array}{r}\text { INCREMENTO } \\
\text { RESP. A VO } \\
(\%)\end{array}$ & TIPO DE FALLA \\
\hline VO & 0 & 11,550 & 6,16 & 0 & $\begin{array}{l}\text { Compresión } \\
\text { hormigón }\end{array}$ \\
\hline V1 & $1(\mathrm{FC})$ & 11,650 & 4,59 & 0.9 & $\begin{array}{l}\text { Rotura refuerzo } \\
\text { bajo carga }\end{array}$ \\
\hline V2 & 2 (FC) & 12,600 & 4,53 & 9.1 & $\begin{array}{l}\text { Rotura refuerzo } \\
\text { bajo carga }\end{array}$ \\
\hline V3 & $3(\mathrm{FC})$ & 12,750 & 4,50 & 10.4 & $\begin{array}{l}\text { Rotura refuerzo } \\
\text { bajo carga }\end{array}$ \\
\hline V4 & $4(\mathrm{FC})$ & 12,800 & - & 10.8 & $\begin{array}{l}\text { Rotura refuerzo } \\
\text { en zona central }\end{array}$ \\
\hline V5 & $5(\mathrm{FC})$ & 15,600 & - & 35.1 & $\begin{array}{l}\text { Compresión } \\
\text { hormigón }\end{array}$ \\
\hline
\end{tabular}


SEGUNDA SERIE

Para la segunda serie de ensayos se elaboraron ocho vigas de menor dimensión. Cuatro de ellas fueron reforzadas con telas y cuatro con láminas pultruídas de fibras de vidrio.

Se decidió elaborar vigas de iguales dimensiones y armaduras que las ensayadas habitualmente en el laboratorio ya que se disponía de una gran cantidad de resultados de ensayos en las vigas sin refuerzo para usar como comparación.

Se utilizaron dos juegos de encofrados y las vigas se fueron hormigonando simultáneamente de a pares. Se elaboraron cuatro vigas con una armadura inferior de $2 \varnothing 12$ (el primer par V1-V1' y el segundo par V2-V2'), luego dos vigas con 2 Ø 10 (V3 y V3') y finalmente el cuarto par con 4 Ø 8 (V4 y V4').

La instrumentación de los ensayos fue similar a la primera serie.

En la siguiente tabla se presentan los resultados. En los renglones indicados como vigas 10 , 30 y 40 se indican los valores promedios y máximos de las cargas de rotura obtenidas en más de veinte ensayos realizados en el laboratorio en los últimos años.

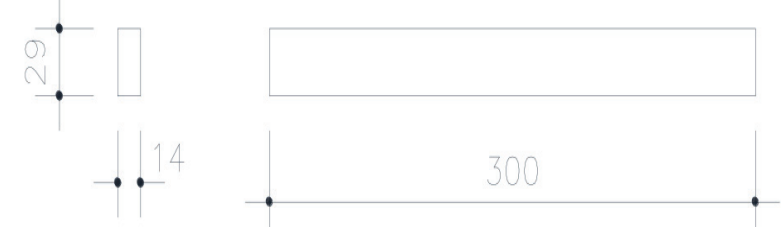

Figura 7. Dimensiones vigas.

TABLA 2. RESUMEN DE RESULTADOS. CARGAS DE ROTURA VIGA $N^{\circ}$ ARMADURA REFUERZO CARGA DE ROTURA

(Kg) $\quad(\mathrm{KN})$

\begin{tabular}{|c|c|c|c|c|}
\hline $1^{0}$ & 2012 Sin refuerzo & Promedio & 4090 & 401 \\
\hline & & Mayor valor & 4540 & 445 \\
\hline
\end{tabular}

22012 Lámina GFRP $5500 \quad 539$

$1^{\prime} \quad 20122$ capas tela GFRP $\quad 4900 \quad 480$

\begin{tabular}{|c|c|c|c|c|c|c|}
\hline \multirow{3}{*}{\multicolumn{2}{|c|}{ 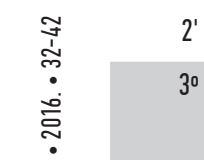 }} & 2012 & 3 capas tela GFRP & & 5450 & 534 \\
\hline & & \multirow[t]{2}{*}{2010} & \multirow[t]{2}{*}{ sin refuerzo } & Promedio & 3450 & 338 \\
\hline & & & & Mayor valor & 3520 & 345 \\
\hline & 3 & 2010 & Lámina GFRP & & 4150 & 407 \\
\hline & $3^{\prime}$ & 2010 & 2 capas tela GFRP & & 4360 & 427 \\
\hline & \multirow[t]{2}{*}{$4^{0}$} & \multirow[t]{2}{*}{408} & \multirow[t]{2}{*}{ sin refuerzo } & Promedio & 3750 & 368 \\
\hline & & & & Mayor valor & 4100 & 402 \\
\hline & 4 & 408 & Lámina GFRP & & 4300 & 421 \\
\hline & $4^{\prime}$ & 408 & 2 capas tela GFRP & & 4200 & 412 \\
\hline
\end{tabular}

TABLA 3. RESUMEN DE RESULTADOS. INCREMENTO DE LAS CARGAS DE ROTURA

\begin{tabular}{rrr}
\hline VIGA No ARMADURA REFUERZO & INCREMENTO & INCREMENTO \\
& al promedio & al mayor valor \\
& $(\%)$ & $(\%)$
\end{tabular}

\begin{tabular}{|rrlrr}
\hline 10 & 2012 & Sin refuerzo & & \\
\hline $1^{\circ}$ & 2012 & Lámina GFRP & 39 & 25 \\
\hline 2 & 2012 & Lámina GFRP & 34 & 21 \\
\hline $1^{\prime}$ & 2012 & 2 capas tela GFRP & 20 & 8 \\
\hline $2^{\prime}$ & 2012 & 3 capas tela GFRP & 33 & 20 \\
\hline $3^{0}$ & 2010 & sin refuerzo & & \\
\hline 3 & 2010 & Lámina GFRP & 20 & 18 \\
\hline $3^{\prime}$ & 2010 & 2 capas tela GFRP & 26 & 24 \\
\hline $4^{0}$ & 408 & sin refuerzo & & \\
\hline 4 & 408 & Lámina GFRP & 15 & 5 \\
\hline $4^{\prime}$ & 4008 & 2 capas tela GFRP & 12 & 2 \\
\hline
\end{tabular}

\section{RESULTADOS Y CONCLUSIONES DE LAS DOS PRIMERAS} SERIES DE ENSAYOS PRIMERA SERIE

El aumento de cantidad de capas de tejidos de fibras de carbono no produjo un aumento significativo en la resistencia de las vigas reforzadas.

Los refuerzos transversales impidieron la delaminación en los extremos. Con respecto a los refuerzos transversales, en los casos en que no se contaba con dichos refuerzos bajo los puntos de aplicación de la carga, fue justamente allí donde se produjo la rotura de las vigas.

En el caso en que se colocaron los refuerzos transversales bajo los puntos de aplicación de las cargas, la rotura se produjo en la zona central de la viga y se obtuvo el máximo aumento de resistencia $(11 \%)$ con una única capa de tejido de fibras de carbono. Esto confirmó la necesidad de colocar los refuerzos transversales intermedios. La viga con refuerzo longitudinal de láminas pultruídas de fibra de vidrio, y refuerzos transversales de tejidos de fibra de carbono (en los extremos y bajo el punto de aplicación de cargas), presentó los resultados de mayor incremento de resistencia $(35 \%)$. Esta viga falló por compresión del hormigón, manteniéndose intactos los perfiles adheridos como refuerzo.

$\mathrm{Al}$ evaluar el costo de la intervención en relación al incremento de resistencia obtenido, el refuerzo con láminas pultruídas resultó el más eficiente. 
SEGUNDA SERIE

En todos los casos se obtuvieron resultados de cargas de rotura superiores tanto al promedio como al valor mayor obtenido sin refuerzo en un gran número de vigas ensayadas anteriormente en el Laboratorio.

Las vigas 3 y 4, reforzadas con láminas pultruídas fueron las primeras en ensayarse y tuvieron una rotura prematura debido a la falla del refuerzo de extremo que no soportó los esfuerzos de tracción (peeling). Debido a esto, se duplicaron los refuerzos de las vigas 1 y 2 provocando la rotura de la viga en la cabeza comprimida y logrando un porcentaje mayor del incremento de carga.

En estos ensayos también se verificó que las láminas pultruídas no mostraron deterioros visibles. Las vigas fallaron por corte.

CONCLUSIONES DE LAS PRIMERAS DOS SERIES

Los resultados obtenidos demostraron la efectividad de las láminas pultruídas de fibra de vidrio para el refuerzo de vigas de hormigón armado evidenciando además la ventaja económica de su utilización.

El costo en el mercado local de los productos de fibra de vidrio es sensiblemente inferior a la opción de productos similares elaborados con fibra de carbono. Esa diferencia de precio compensa con creces la necesidad de colocar mayor cantidad de material para alcanzar las mejores propiedades mecánicas que presentan las fibras de carbono.

Este tipo de refuerzos encuentra su aplicación más provechosa en elementos subarmados que permiten un desarrollo ulterior de su $\mathrm{ca}^{-}$ beza comprimida. Otra limitación importante a tener en cuenta para lograr la efectividad del refuerzo es la capacidad sobrerresistente al corte que presenta la viga, si bien en este caso también puede realizarse un refuerzo mediante telas o láminas.

Las láminas pultruídas presentan una resistencia a la tracción muy elevada, es prácticamente imposible lograr su rotura en un ensayo de flexión por lo que se puede deducir que la falla siempre resultará en el anclaje de la misma salvo que la viga rompa por corte o por compresión del hormigón.

Se decidió entonces profundizar la investigación de los sistemas de anclaje de dichas láminas en una tercera serie de ensayos.

TERCERA SERIE

Se ensayaron conjuntos compuestos por dos probetas de hormigón armado sujetadas ambas a un sistema de perfiles de acero articulados con el objetivo de que al aplicar una carga en la rótula, todo el esfuerzo sea traducido en tracción en la zona inferior del sistema (zona donde esta adherido el refuerzo).

La fuerza de tracción a la que es sometida la lámina de PRFV se rige por la siguiente fórmula:

$$
F=\frac{P x L}{4 x h}
$$

donde

P: fuerza aplicada del gato hidráulico.

L: luz entre los apoyos.

$\mathrm{H}$ : brazo de palanca entre la lámina de PRFV y la rótula (punto donde se aplica la carga).

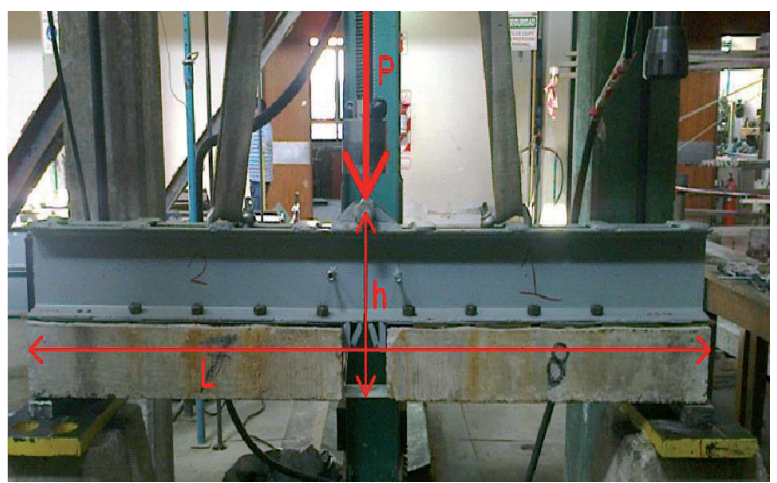

Figura 8. Dispositivo de ensayo y dimensiones.

Se prepararon distintos sistemas de anclaje:

a. Solamente adheridos con resina epoxi (dos conjuntos)

b. Reforzados en los extremos con telas unidireccionales de fibra de vidrio (dos conjuntos)

c. Fijados con bulones (sistema de anclaje de expansión). En este caso hubo 3 va- $^{-}$ riantes:

- 1 bulón común $\varnothing 8 \mathrm{~mm}$ en cada extremo. (un conjunto)

- 1 bulón 8,8 (A325) Ø 8 mm en cada extremo. (un conjunto)

- 2 bulones 8,8 (A325) Ø 8 mm en cada extremo (dos conjuntos)

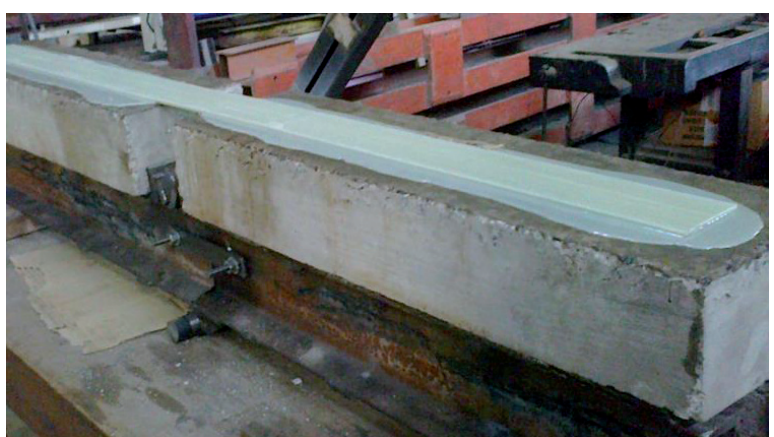

Figura 9. Sistema de anclaje a). 


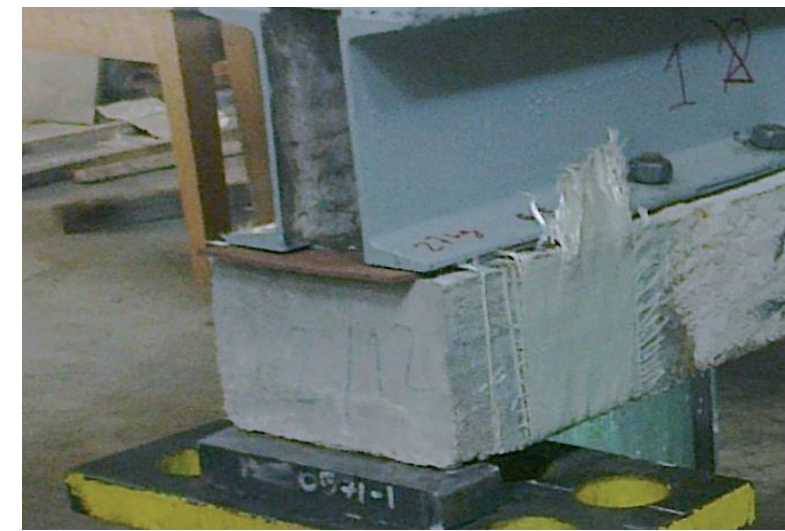

Figura 10. Sistema de anclaje b).

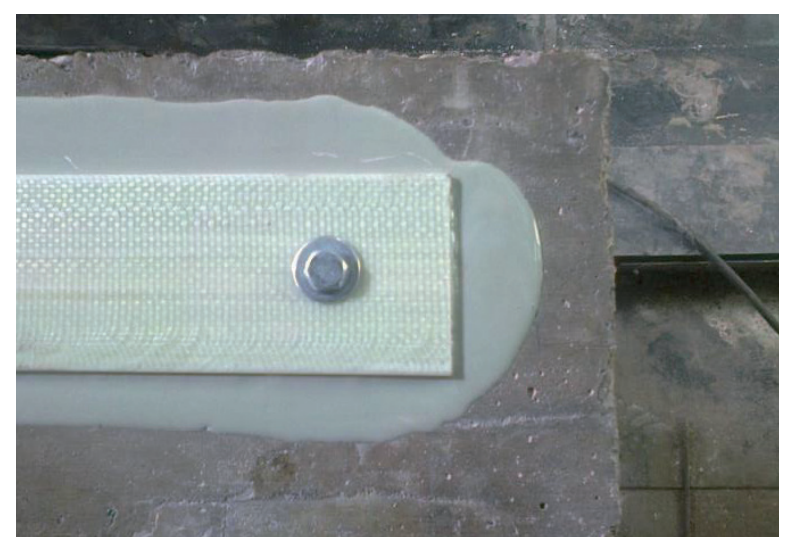

Figura 11. Sistema de anclaje c). 1 bulón común.

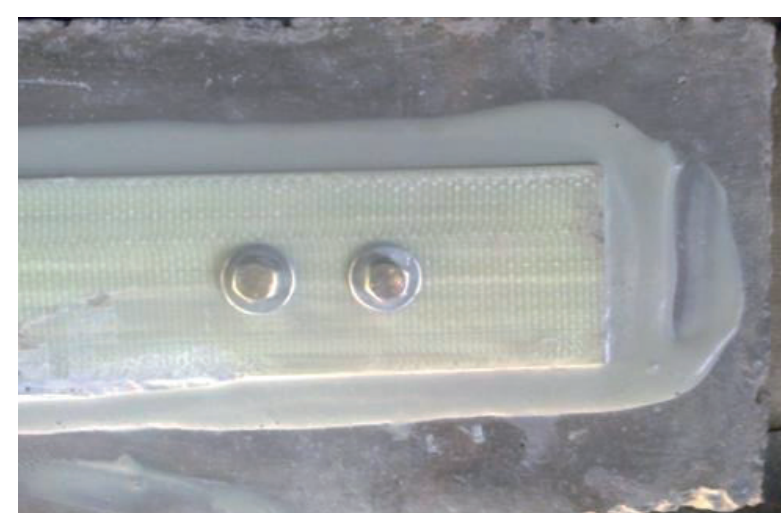

Figura 12. Sistema de anclaje c). 2 bulones 8.8 .

ENSAYOS

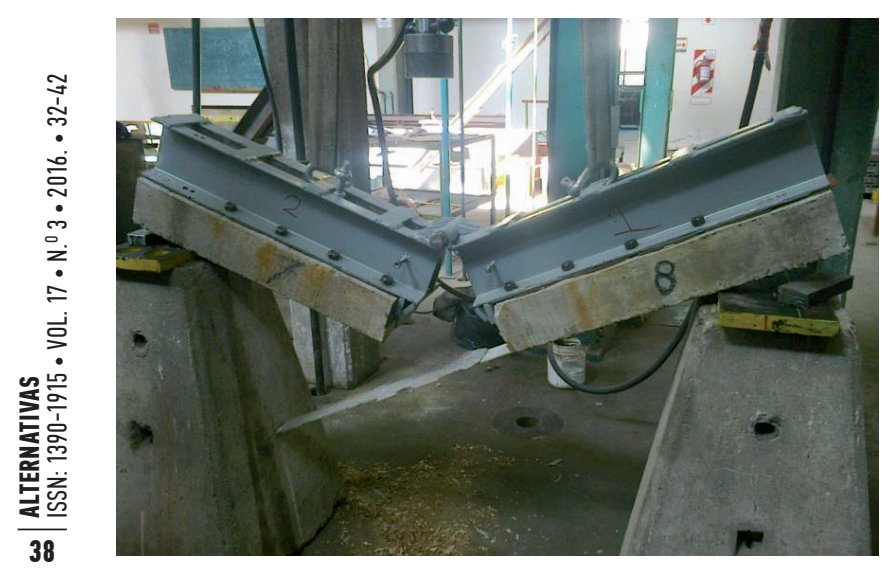

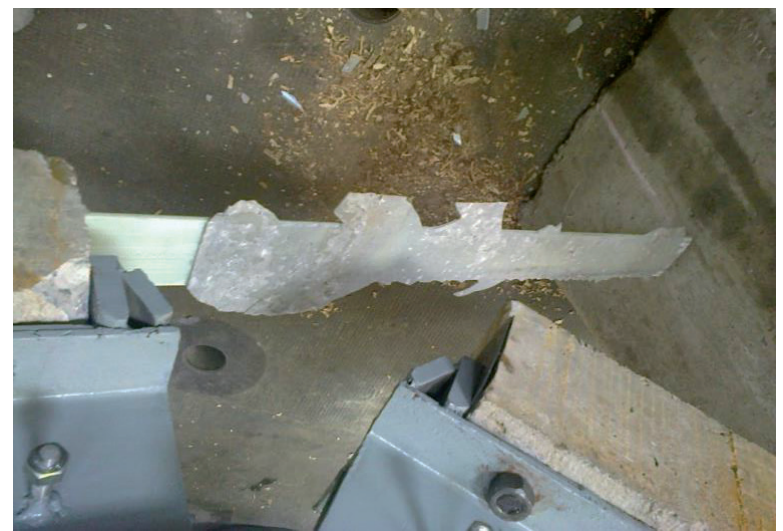

Figura 13. Ensayo $n^{\circ} 1$, Lámina adherida sin refuerzos de anclaje.
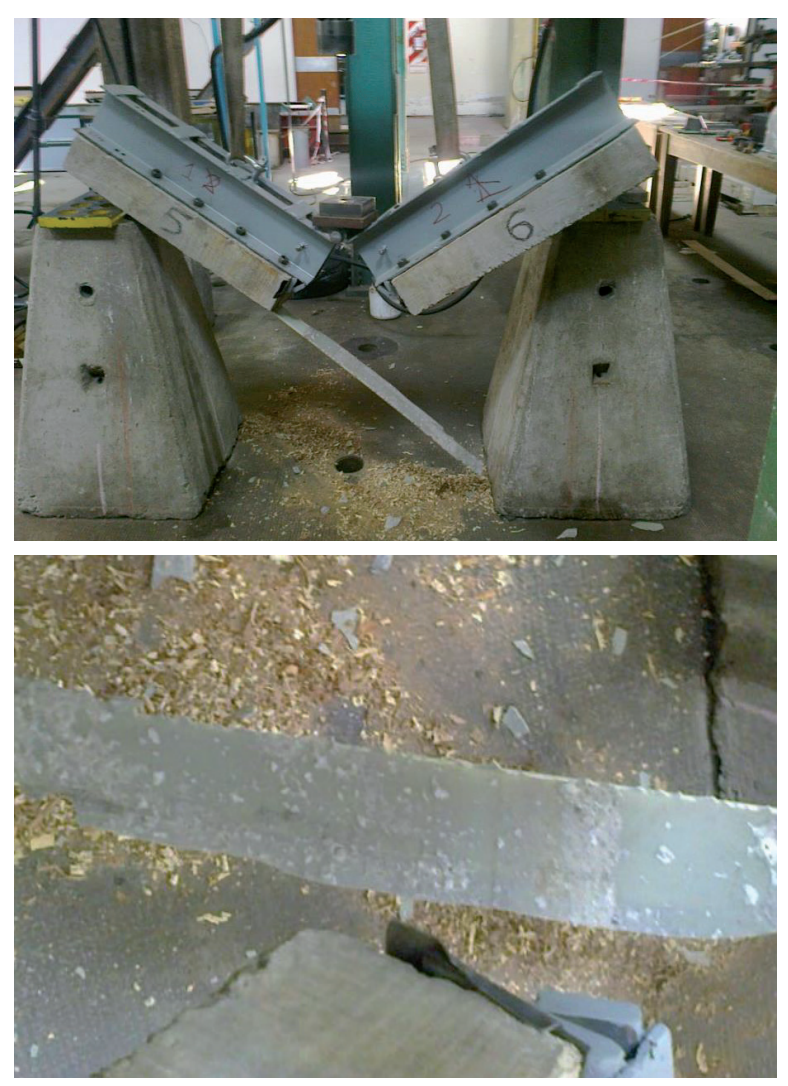

Figura 14. Ensayo $n^{\circ} 2$, Lámina adherida sin refuerzos de anclaje.

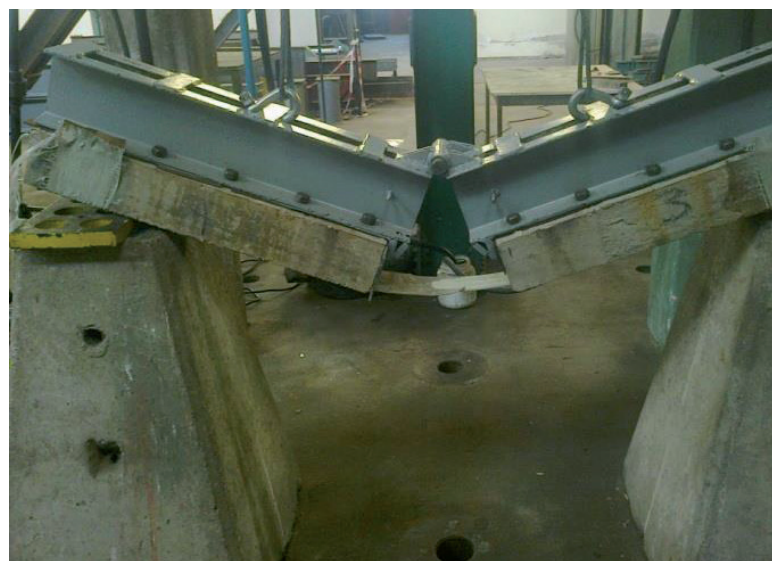




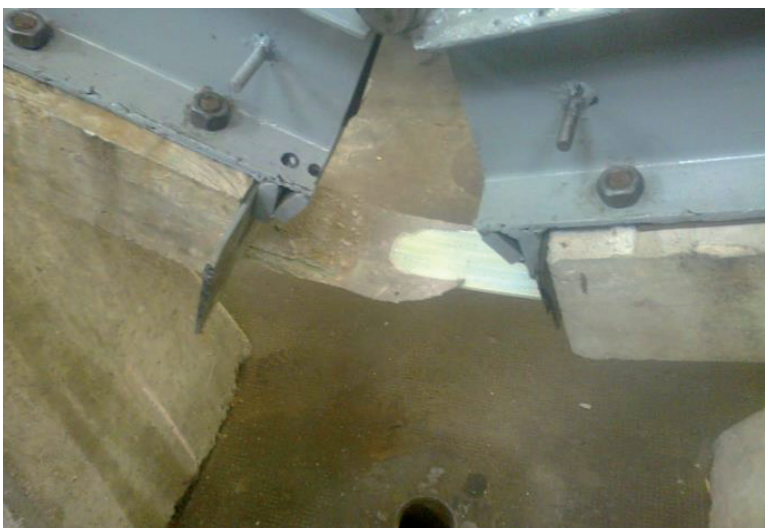

Figura 15. Ensayo n 3 Lámina con refuerzos de telas en los extremos.
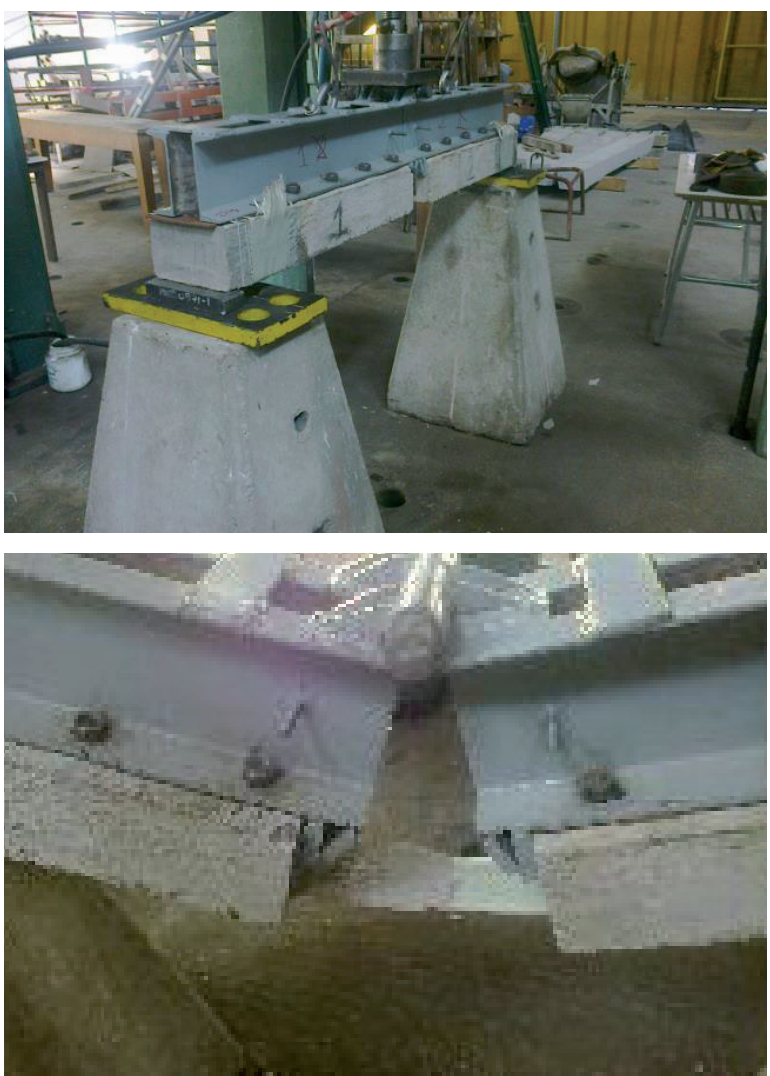

Figura 16. Evsayo n 4 Lámina con refuerzos de telas en los extremos.

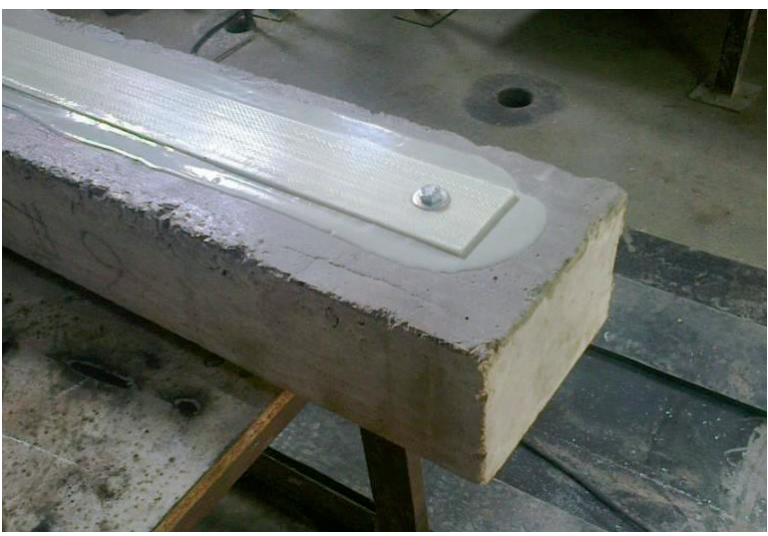

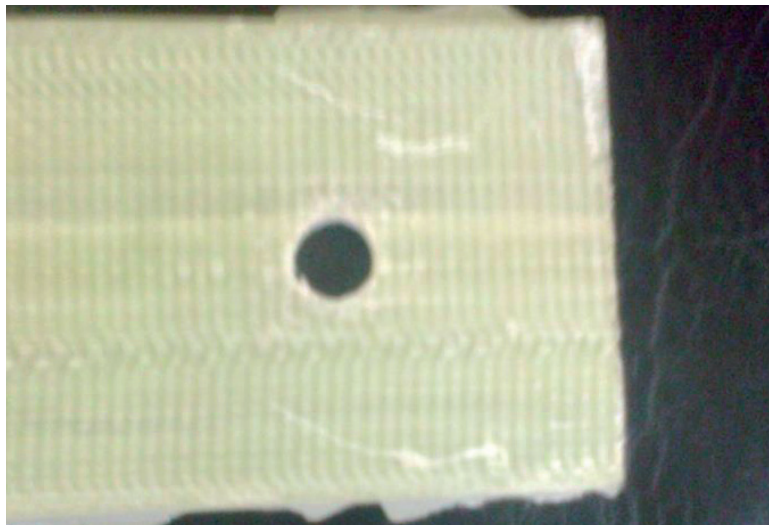

Figura 17. Ensayo n 5 Lámina con un bulón común en cada extremo.

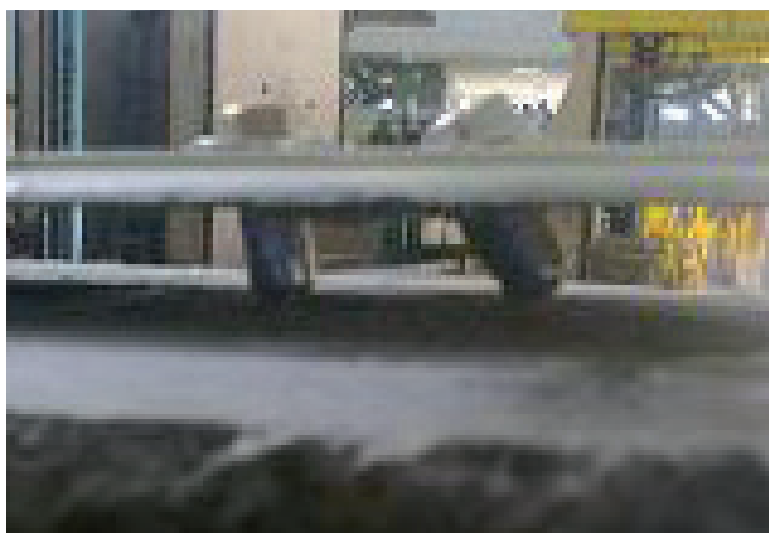

Figura 18. Ensayo n ${ }^{\circ} 6$ Lámina con dos bulones 8.8 en cada extremo.
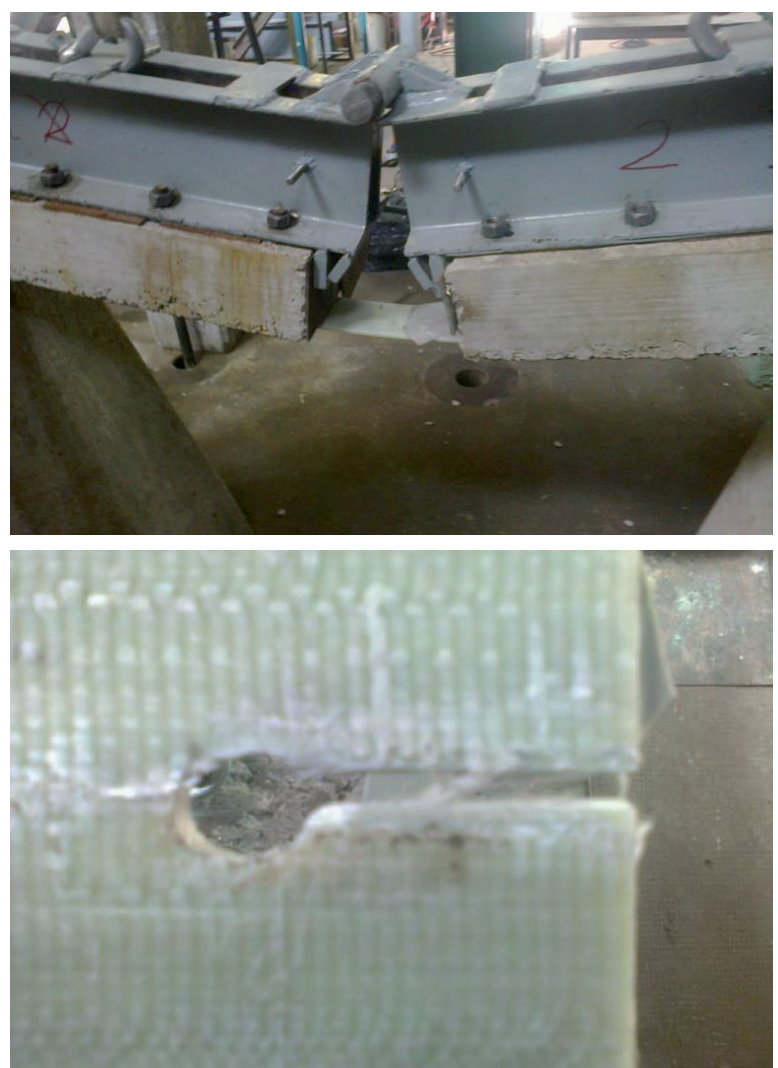

Figura 19. Ensayo n 7 Lámina con un bulón 8.8 en cada extremo. 


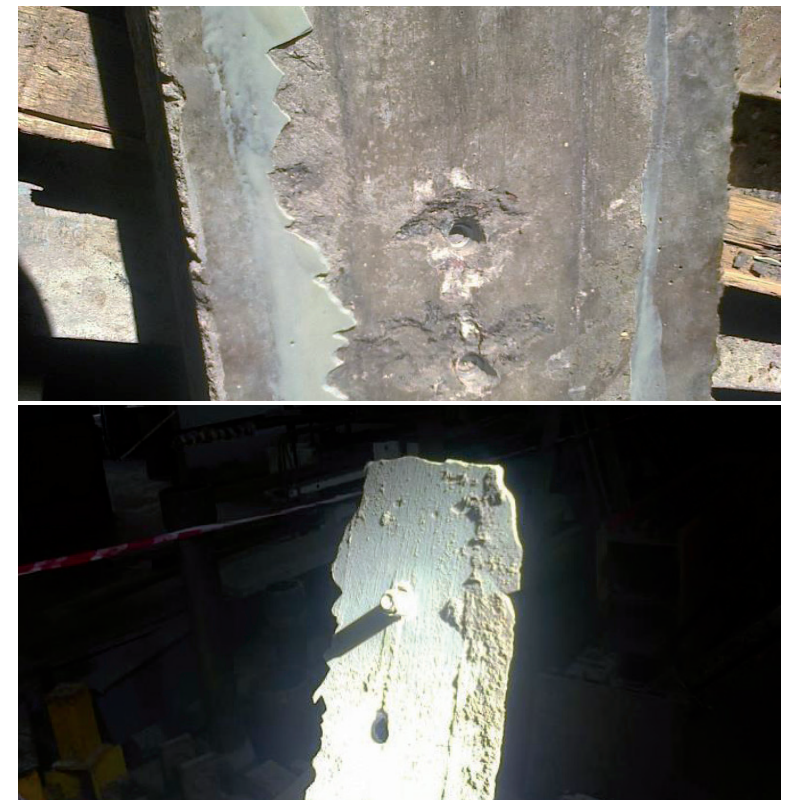

Figura 20. Ensayo n 8 Lámina con dos bulones 8.8 en cada extremo.

\section{RESULTADOS Y CONCLUSIONES DE LA TERCERA SERIE RESULTADOS DE LOS ENSAYOS}

A continuación se presenta una tabla con los resultados de cada ensayo, en la cual se detalla el sistema de adherencia, la carga de rotura y observaciones sobre el tipo de rotura:

\section{TABLA 4. RESULTADOS DE LA TERCERA SERIE}

\begin{tabular}{|c|c|c|c|c|c|}
\hline $\begin{array}{r}\text { ENSAYO } \\
\text { No }\end{array}$ & $\begin{array}{l}\text { SISTEMA DE } \\
\text { ADHERENCIA }\end{array}$ & $L(M)$ & P (KN) & $F(K N)$ & TIPO DE ROTURA \\
\hline 1 & resina & 1,56 & 440 & 545 & $\begin{array}{l}\text { Despegado de la banda } \\
\text { - colapso }\end{array}$ \\
\hline 2 & resina & 1,57 & 358 & 446 & $\begin{array}{l}\text { Despegado de la banda } \\
\text { - colapso }\end{array}$ \\
\hline 3 & $\begin{array}{l}\text { resina + tela } \\
\text { en extremos }\end{array}$ & 1,57 & 505 & 629 & $\begin{array}{l}\text { Despegado de la banda - } \\
\text { corte de la tela - colapso }\end{array}$ \\
\hline 4 & $\begin{array}{l}\text { resina + tela } \\
\text { en extremos }\end{array}$ & 1,58 & 366 & 459 & $\begin{array}{l}\text { Despegado de la banda - } \\
\text { corte de la tela - colapso }\end{array}$ \\
\hline $5\left(^{*}\right)$ & $\begin{array}{l}\text { resina }+1 \\
\text { bulón común } \\
\text { de cada lado }\end{array}$ & 1,57 & 285 & 355 & $\begin{array}{l}\text { Despegado de la banda - } \\
\text { corte del bulón - colapso }\end{array}$ \\
\hline 6 & $\begin{array}{l}\text { resina }+2 \\
\text { bulones } 8.8 \\
\text { de cada lado }\end{array}$ & 1,57 & 410 & 511 & $\begin{array}{l}\text { Despegado de la } \\
\text { banda - arranque de } \\
\text { los bulones - capacidad } \\
\text { resistente post rotura }\end{array}$ \\
\hline 7 & $\begin{array}{l}\text { resina }+1 \\
\text { bulón } 8.8 \text { de } \\
\text { cada lado }\end{array}$ & 1,58 & 567 & 711 & $\begin{array}{l}\text { Despegado de la } \\
\text { banda - ojalado de la } \\
\text { lámina - no cortó los } \\
\text { bulones - capacidad } \\
\text { resistente post rotura }\end{array}$ \\
\hline 8 & $\begin{array}{l}\text { resina }+2 \\
\text { bulones } 8.8 \\
\text { de cada lado }\end{array}$ & 1,58 & 355 & 445 & $\begin{array}{l}\text { Despegado de la } \\
\text { banda - arranque de } \\
\text { los bulones - capacidad } \\
\text { resistente post rotura }\end{array}$ \\
\hline
\end{tabular}

(*) Esta probeta tuvo un problema durante la manipulación y se despegó parte de la lámina por lo que se suponía que el resultado no iba a ser representativo. De todos modos este ensayo sirvió para descartar la utilización de los sistemas de anclajes comerciales con bulones comunes.

\section{CONCLUSIONES DE LA TERCERA} SERIE DE ENSAYOS

De los resultados obtenidos se pueden sacar las siguientes conclusiones:

- La carga de rotura obtenida por el encolado simple no fue notablemente incrementada por el mejoramiento del anclaje en los extremos con excepción del ensayo no 7 en el que se produjo el ojalamiento de la planchuela sin cortar los bulones.

- El anclaje con bulones mostró una buena capacidad de resistencia post crítica que le confiere a las estructuras una característica de ductilidad muy útil en zonas sísmicas.

- La falla de los anclajes con bulones de alta resistencia se produjo siempre por el arranque de los mismos, nunca se cortaron.

- En el único ensayo en el que no se desprendieron los bulones (ensayo no 7) se obtuvo el mayor valor de la carga de rotura.

- En este tipo de ensayos, al producirse el giro independiente de las dos probetas vinculadas por la rótula, resultan despreciables los esfuerzos de tracción por deformación elástica diferenciada entreviga y refuerzo (peeling). Este tipo de fenómeno se estudiará en las siguientes etapas en ensayos con vigas.

La falla de arrancamiento de los bulones que demostró ser el punto débil de este sistema de vinculación puede corregirse utilizando anclajes más profundos. Éste es uno de los objetivos de la cuarta serie de ensayos.

\section{CUARTA SERIE}

El objetivo de esta cuarta serie era validar el sistema de anclajes con pernos más profundos. Como se trataban de ensayos de aproximación, se reciclaron las probetas anteriores que habían quedado prácticamente intactas sabiendo que los valores a obtener iban a servir solamente de manera orientativa para comprobar el funcionamiento de dichos pernos.

Se prepararon siete probetas con 2 varillas $8.8 \varnothing 10 \mathrm{~mm}$ embebidas en el hormigón 80 $\mathrm{mm}$. Estas varillas superaban el espesor de recubrimiento penetrando en el núcleo de la probeta.

Se utilizaron varillas lisas. En una etapa posterior se piensan utilizar varillas roscadas 

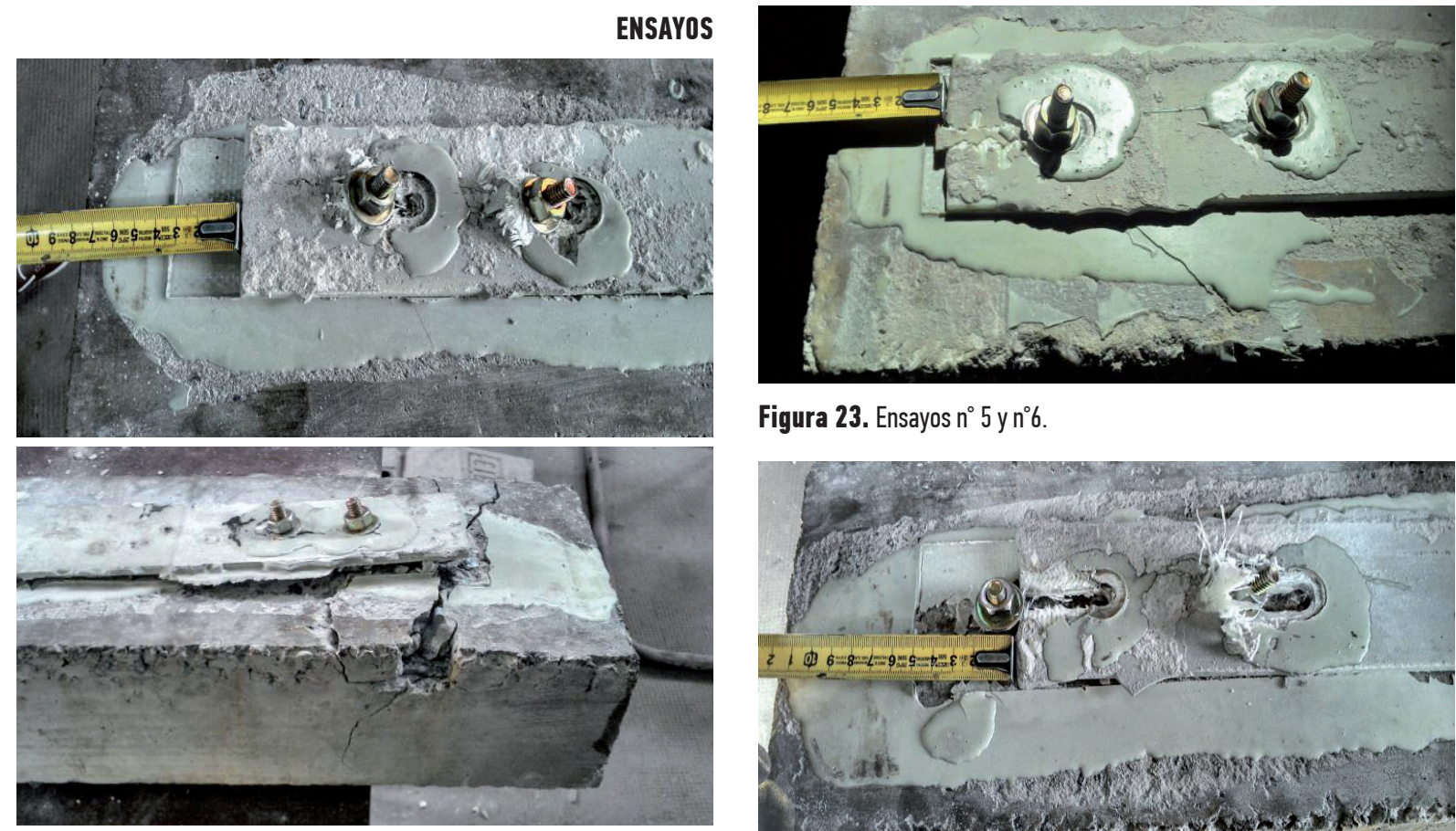

Figura 23. Ensayos $n^{\circ} 5$ y $n^{\circ} 6$

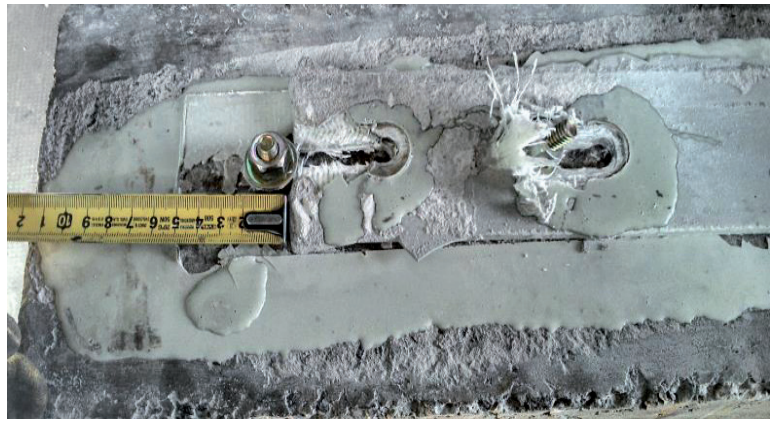

Figura 21. Ensayos $n^{\circ} 1 \mathrm{y} \mathrm{n}^{\circ} 2$.

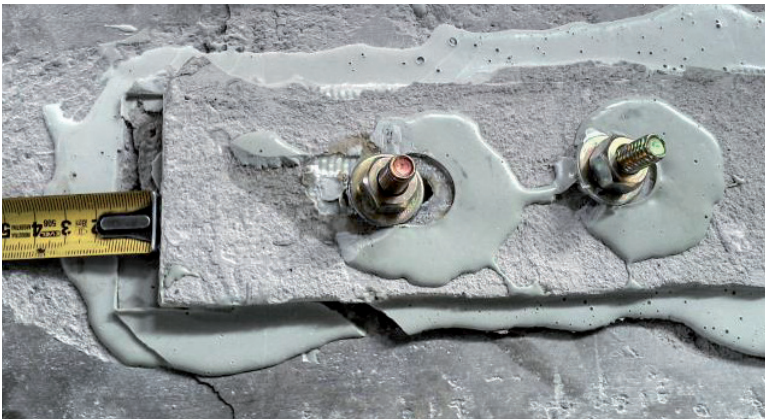

Figura 24. Ensayo n 7

\section{RESULTADOS Y CONCLUSIONES DE LA CUARTA SERIE RESULTADOS DE LOS ENSAYOS}

A continuación se presenta una tabla con los resultados de cada ensayo, en la cual se detalla la carga última, la fuerza de adherencia, la carga de 1o falla, la carga resiliente, la relaciones entre la carga última y la carga de primera falla con la carga última promedio obtenida con las láminas solamente adheridas. Esta carga promedio es $\mathrm{Pu} 0=(440+358) / 2=399 \mathrm{kN}$

Se indica también el tipo de rotura que se verificó en cada caso.

\section{TABLA 5. RESULTADOS DE LA CUARTA SERIE}

\begin{tabular}{|lrrrrrrrr}
\hline ENSAYO No & & $\mathbf{1}$ & $\mathbf{2}$ & $\mathbf{3}$ & $\mathbf{4}$ & $\mathbf{5}$ & $\mathbf{6}$ & $\mathbf{7}$ \\
\hline L & $(\mathrm{m})$ & 1,535 & 1,575 & 1,56 & 1,53 & 1,54 & 1,54 & 1,545 \\
\hline Púltima & $(\mathrm{kN})$ & 537 & 790 & 632 & 505 & 615 & 538 & 532 \\
\hline F & $(\mathrm{kN})$ & 654 & 988 & 782 & 613 & 752 & 658 & 652 \\
\hline P 10 falla & $(\mathrm{kN})$ & 490 & 475 & 510 & 390 & 485 & 475 & 495 \\
\hline P resiliente & $(\mathrm{kN})$ & 360 & 750 & 350 & 300 & 360 & 370 & 160 \\
Pu / Pu0 & $(\mathrm{kN})$ & 1,35 & 1,98 & 1,58 & 1,27 & 1,54 & 1,35 & 1,33 \\
\hline P1of / PuO & $(\mathrm{kN})$ & 1,23 & 1,19 & 1,28 & 0,98 & 1,22 & 1,19 & 1,24 \\
\hline
\end{tabular}

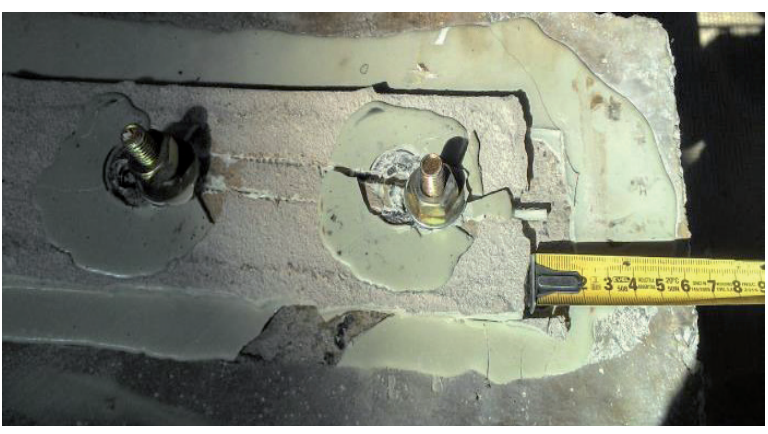

\section{ENSAYO NO TIPO DE ROTURA}

1 Despegado de la banda - ojalamiento $3 \mathrm{~cm}$

2 Despegado de la banda - desgarro en la zona de anclaje

3 Despegado de la banda - ojalamiento $1,5 \mathrm{~cm}$

4 Despegado de la banda - ojalamiento $8,5 \mathrm{~cm}$

5 Despegado de la banda - ojalamiento $2 \mathrm{~cm}$

6 Despegado de la banda - ojalamiento $1 \mathrm{~cm}$

7 Despegado de la banda - ojalamiento $5 \mathrm{~cm}$ 
CONCLUSIONES

El objetivo de este trabajo, todavía en curso, es comprobar la efectividad de un sistema de refuerzo estructural que sea económicamente viable para su utilización masiva. En efecto, como se mencionó, el alto costo de las láminas pultruídas de fibras de carbono impidió la difusión de su utilización en el mercado local y es por eso que decidimos experimentar con láminas de fibras de vidrio de fabricación nacional que tienen un costo notablemente inferior.

Además de su resistencia mecánica, las láminas de fibra de vidrio presentan la ventaja de poder vincularse a las estructuras con bulones que aseguran el anclaje al núcleo de hormigón entre armaduras; de esta manera no se depende solamente de la resistencia a tracción del recubrimiento. Además, este tipo de vinculación es notablemente más efectiva que las bandas de tela en U para absorber los esfuerzos de tracción por deformación elástica diferenciada entre viga y refuerzo (peeling).

Si bien este sistema de anclajes presenta la dificultad de tener que atravesar la zona inferior de vigas donde muchas veces la densidad de armaduras no permite el fácil acceso, general-

\section{REFERENCIAS BIBLIOGRÁFICAS}

1. Aguiar R., A. Busnelli, P.Caiza, A.Haro, R.Seracino, M.Tornello, J.C.Vielma(2014)-Ponencias II Curso Internacional Avanzado de FRP.

2. Busnelli A.P., R.E.López, M. del Rio (2014) Refuerzo de vigas de hormigón armado con láminas de PRFV" - 230 Jornadas de Ingeniería Estructural.

3. Lamanna A.J., L.C.Bank, D.T.Borowicz, D.Arora (2003) - Strengthening of concrete beams with mechanically fastened frp strips - University of Wisconsin, Madison USA.

4. Leeming M.B., J.J.Darby (1998) Design and specifications for FRP plate bonding of beams.

5. Molina M., J.P.Gutiérrez, C.López (2008) Consideraciones acerca del empleo de láminas de fibras de carbono aplicadas al campo de las estructuras.

6. Ohelers D.J., M.S.Mohamed Ali, M.Haskett, M.C.Griffith (2008) A partial-interaction ductility model for FRP plated RC flexural members. mente se suele disponer de la información sobre la distribución de armaduras y, si no es así, se puede verificar esta distribución picando el recubrimiento.

Desde el punto de vista de su resistencia mecánica, como era de esperar, los resultados obtenidos demostraron la efectividad de las láminas pultruídas de fibra de vidrio para el refuerzo de vigas de hormigón armado evidenciando además la ventaja económica de su utilización.

Con respecto a los refuerzos en los extremos de las láminas, se pudo comprobar la ventaja de la resistencia post crítica que presenta la vinculación abulonada al otorgar ductilidad al refuerzo permitiendo la disipación de energía necesaria en estructuras sometidas a solicitaciones sísmicas. Si se extendiera esta vinculación a toda la longitud del refuerzo se lograría incrementar notablemente este fenómeno.

En la cuarta serie de ensayos al trabajar con bulones más largos se incrementó la carga de primera falla y mucho más la carga de rotura. Además, las probetas demostraron una importante carga resiliente y en ningún momento se produjo el colapso total del sistema.

7. Visintini S., Busnelli A.P.(Director) (2013) - Refuerzo de vigas de hormigón armado con materiales compuestos adheridos exteriormente" - Proyecto Final - Fac. Cs. Exactas, Ingeniería y Agrimensura U.N.R.

8. Wei A., H.Saadatmanesh, M.R.Ehsani (1994) RC Beams strengthened with FRP plates.

9. Normas y reglamentos.

10. ACI 440.2R-08 (2008) - Guide for the Design and Construction of Externally Bonded FRP Systems for Strengthening Concrete Structures.

11. CNR-DT 200 (2004) - Istruzioni per la Progettazione, l'Esecuzione ed il Controllo di Interventi di Consolidamento Statico mediante l'utilizzo di Compositi Fibrorinforzati.

12. Seismic FRP Task Group (2010) Seismic Strengthening of Concrete Buildings Using FRP Composites. 